\title{
Situational and Mixed Business Strategy Analysis for Market Competitiveness: An Exploration in Context of Africa
}

\author{
Desalegn Yeshitila $^{1} \cdot$ Daniel Kitaw $^{1}$ (D) Kassu Jilcha $^{1}$ (D) Mamo Muchie $^{2}$ (D)
}

Received: 10 January 2020 / Accepted: 23 July 2020 / Published online: 15 October 2020

(c) Global Institute of Flexible Systems Management 2020

\begin{abstract}
The purpose of this study is to review various business strategy options and the experience of some of the companies out there who have managed to create a new market space in already declining and saturated industry. Irrespective of sizes of companies, small, medium or large, it is customary to evolve a business strategy, in order to set the future strategic position of the firm in the marketplace in terms of product and service offering, pricing and growth strategy. An organization could have an ideal strategy formulation in place, but without proper implementation mechanism it would be waste of resource and time and a pointless effort that could not produce the expected result. The research methodology employed in this study is literature review of peer reviewed articles published in quality journals. The analysis and discussion led to findings that there is always a room for incremental innovation and customer value proposition that would lead to create a new demand and market space. Moreover, there is no 'one size fit' strategy that would give winning edge for businesses, rather situational approach and combined strategy option could be the approach recommended.
\end{abstract}

Keywords Product and service delivery innovation · Red ocean strategy $\cdot$ Blue ocean strategy $\cdot$ Competitive advantage $\cdot$ Continuous improvement $\cdot$ Mixed strategy

\section{Introduction}

This paper discusses various theories on business strategy such as the Blue Ocean strategy, the Red Ocean, business core competence and lean strategy. Options of Strategy formulation and implementations were the topic of interest for this discussion. The research question raised is "what are strategy options for firms to create a new market space in already declining and saturated industry', 'How can SubSharan African countries Strategically and uniquely position

Kassu Jilcha

jkassu@gmail.com

Desalegn Yeshitila

desuselam@yahoo.co.uk

Daniel Kitaw

danielkitaw@yahoo.com

Mamo Muchie

mamomuchie@gmail.com

1 School of Mechanical and Industrial Engineering, Addis Ababa Institute of Technology, Addis Ababa University, Addis Ababa, Ethiopia

2 Pretoria Universities, Pretoria, South Africa themselves in a global market environment, given the business market challenges and opportunities prevailing in the region'.

The authors have hands-on experience about the distinct challenges' businesses in Sub-Sharan African countries facing. Generic strategy option might not be fit enough for enormous challenges business in the region undergoing. The specific and unique dynamism and volatility practiced needs a business strategy appropriate for the challenges and opportunities the business environment has to offer.

The developing countries have many challenges specifically in Sub-Sharan African Countries. Some of the challenges these countries facing are such as unemployment and underemployment, underinvestment in infrastructure, fiscal crises, political change and climate change. These factors are putting challenging efforts on business competitiveness as stated in this literature.

The study by World Economic Forum on Africa (2018) that Sub-Sharan African countries are one of the world's regions paying high price for climate change. The region is also affected by sporadic tribal conflicts for access to resources and gorilla fighting for various political reasons. All these factors lead to businesses supply chain disruption 
that need external environment situation analysis and align the business strategy to fit volatility and uncertainty facing the business entity.

Given the challenges, Sub-Sharan African countries still offer one of the best global business opportunities with high margin to make. Some of the opportunities are a population that is fast growing and urbanizing, Africa is industrializing, huge infrastructure construction undergoing, abundance agricultural and mineral resources, increasing digitalization and numerous active mobile users. (Leke et al. 2018; Landry Signe 2018; Smit 2010; Porter 1990).

One of the pitfalls in business strategy formulation and selection is directly copying the strategy of market leaders and pioneer organization without considering the context of own organization. Moreover, organization tend to choose one strategy option in the expense of the other as if sticking to one and only one option would be a must, combined and mixed business strategies in the context of own organization internal and external factors, industry and market situations are the perspective of this paper.

It is imperative to consider the internal and external market environment of the firm where it operates to consider the strategy direction which would best fit the firm's product and service offerings, the saturation and competition level of the existing market, and above all, the customer's value propositions. In line with this various scholars' points of view on Blue Ocean, Red ocean, core competence and recently lean strategies were reviewed. Porter (1979) Five Forces model were groundbreaking piece of work, where most of alternative strategy propositions have made their base in one way or another. For example, Wilde and Hax (2001) proposed the Delta Model. The resource- based view (RBV) where businesses competitive advantage is the main factor of valuable, tangible or intangible resources at the business' disposal (Wernerfelt 1984; Rumelt 1984).

Likewise, the dynamic capability view Teece (1997) described firm's strategy as firm's ability to integrate, build and reconfigure internal and external competences to address rapidly changing environments. Kim and Mauborgne (2005) in their book called 'Blue Ocean Strategy' proposed totally different approach to strategy, arguing that the competitive approach of strategy are not the ideal ways for firms to pursue. The authors argued constructing their different incite on case studies on value innovation. They designed strategy canvas, a diagnostic framework as a guide to execute a Blue Ocean Strategy by making the competition irrelevant. The Blue Ocean Strategy could be metaphor to sailing on unchartered Blue Ocean with access to new market, with unforeseen risks minimizing mechanism in place. To stay out of the crowed and, hence the competition, value innovation is the prerequisite, and the sustainable way to make the competition irrelevant. As a result of value innovation cost is minimized significantly and driving customer value up.
Contrary to the blue ocean the red ocean focuses on existing demand and market space and the main strategy is to win and beat the competition and 'snatch' as much portion of the existing pie as possible. Red ocean works under the principle of value-cost trade off (Porter 1980).

Relative to the above two types of strategies lean strategy is a contemporary view of strategy where the basis of the strategy is respect for people or people centric strategy (Michael et al. 2017). A lean organization is a learning organization that continously strive to develop culture of problem solving and customer value innovation through kaizen, experimentation and employee engagement.

Prahalad and Hamel (1990), asserted different approach to companies' competitiveness, that is through core competence, where multiple combination of resources and employees skills could distinguish a firm in the market competition. According to Prahalad and Hamel (1990) core competencies fulfill three measures, that are: potential access to a wide variety of markets, end product should contribute to the target customer benefits, products and services are difficult to imitate by competitors.

More to the option of strategy management tools is the balanced scorecard (BSC), originally framed by Kaplan and Norton in 1992. The approach has been adapted over the years, gaining popularity all over the world (Hasan and Chyi 2017; Hansen and Schaltegger 2016). It is a holistic approach to strategy measures going beyond the traditional financial measures including customer, learning and growth, internal business processes perspectives. Quesado et al. (2018) argue that BSC is more than a simple performance evaluation system, to become a true strategic management tool able to clarify and translate the mission and organizational strategy, making possible the communication process, the strategic alignment and the organizational learning.

In addition to the above-mentioned strategy approaches strategy diamond is also a noble contribution to strategy options by Hambrick and Fredrickson (2005). The authors assert that if a business must have a single, unified strategy, then it must necessarily have parts. The authors divide those parts into five. They present a framework for strategy design, arguing that a strategy has five elements, providing answers to five questions - arenas: where will the company be active? vehicles: how will the company get there? differentiators: how will the company win in the marketplace? staging: what will be the company's speed and sequence of moves? economic logic: how will the company obtain its returns? According to the study by Morteza Valiollahpour et al. (2014) showed that the stratergy diamend model are important to consider the changing of the situation to include are basic factors that bring competitiveness in the market situation.

Organizations' strategy formulation is equally important to the implementation effort in order to achieve the main 
goal of strategy as business competitive advantage (Fai pun 2004).

Therefore, the purpose of this study is to identify matching business strategy options for various situations. In some situations, a single strategy option may not be good enough or to the worst case could starve business from harvestings benefits by aligning resources to the demanding external and internal situations.

The paper's remaining sections deal with literature review, methodology, result, discussion and concluding remarks.

\section{Literature Review}

Scholarly articles published by various authors, written on the topics of Blue Ocean, Red Ocean and lean strategy was reviewed. By no means, the literature review was exhaustive. Articles published recently, and articles found to be founding works in strategy options were preferentially selected.

The development of theories that help explain competitive advantage has occupied the attention of the business community for the better part of half a century (Wang 2014). This section aims to provide an overview of the key theories in this space. Wang (2014) asserted that in the early period, there were two dominant theories of competitive advantage: The Market-Based View (MBV) and the Resource-Based View (RBV). The notion of core competencies is closely related to the resource-based view of strategy (Arnoldo and Dean 2001). The knowledge-based view and capability-based view of strategy have also been derived from the resource-based view. Hanningtone (2013) argue that tangible resources should possess the characteristics of rarity, valuability, inimitability and un-substitutability which create sustainable competitive advantage and include state-of-the-art modern showrooms, service workshops, financial resources, spare parts warehouses and human resources.

Michael Porter defines strategy as competitive market position, "deliberately choosing a different set of activities to deliver a unique mix of value." Business firms need to know their competitors value offerings so that they could avoid head on competition by reacting in a different value preposition to win in their own context instead of simply benchmarking the competition.

Business strategy gives a company to place the firm's direction in a unique positioning so that the company wins the competition in its own way focusing on the customers' product and service value which the company offers based on the firm's internal capability and capitalizing on the external market environment opportunities.

Blue Ocean Strategy encourages companies to break out of fierce red ocean competition by creating uncontested market space, with a new demand for the products and services through value innovation (Andrew 2009; Renee et al. 2005; James et al. 1990). The proponents argue that benchmarking the competition is not a wise thing to do while the competition is experiencing shrinking demand and head-to-head competition where the rules of the game could lead to some to win and some others to lose. Relatively new and a different approach to what has been well established theory of strategy, the Blue ocean strategy, has been developed by Kim and Mauborgne (2005) which in a short time gained global acceptance and popularity.

The Red Ocean strategy is the common one for most firms. As the competition is fierce it could be challenging for most of the companies to grow and expand their market share. A typical example of saturated market space, and competitive industry is the airlines industry. European lowcost carrier Ryanair is competing very successfully in the already saturated Red ocean airline industry. The company pursues low cost Business, by employing methods such as using secondary airports, avoiding expensive busy main airports, online booking, online check-in, and charging extra fee for almost every extra service, like in cabin entertainment, refresher and carrying checked in bags (Ryanair 2019).

The basis of Blue Ocean Strategy is value innovation where the firm breaks out of the fierce competition and set its own rules by creating a new demand, where there would be a win-win situation for both customers through value addition and for the firm by giving a niche advantage of uncontested market environment by making the competition irrelevant.

As Kim and Mauborgne (2005) stated value innovation is an aspect that could be realized in a product, service and delivery which must match with the value of the customer and at the same time take a cost advantage position by eliminating any features that are taken as granted and keep to the standard those features not priority to the customer, to the normal standard.

Kim and Mauborgne (2005) devised strategy Canvas. The main focus of Strategy Canvas is eliminate the elements in value proposition that are taken for granted, reduce products and services that are higher than the industry standard, raise the factors that create value for the buyers and sellers and create those items never been created in the market space and industry (Kim and Mauborgne 2005).

The strategy canvas is both a diagnostic and an action framework for building a compelling Blue Ocean Strategy. It serves two purposes. First, it captures the current state of play in the known market space. This allows a firm to understand where the competition is currently investing, the factors the industry currently competes on in products, service, and delivery, and what customers receive from the existing competitive offerings on the market (Alukal 2017; Mohammad et al., 2015; Kim and Mauborgne 2005). 
Table 1 Four actions framework of Cirque du Soleil blue ocean strategy (Kim and Mauborgnered 2005)

\begin{tabular}{|c|c|c|c|}
\hline Eliminate & Reduce & Raise & Create \\
\hline Star performers & Fan and humor & Unique venue & Theme \\
\hline Animal shows & Thrills and danger & & $\begin{array}{l}\text { Artistic } \\
\text { music } \\
\text { and } \\
\text { dance }\end{array}$ \\
\hline \multicolumn{4}{|l|}{ Aisle concessions } \\
\hline $\begin{array}{l}\text { Multiple show } \\
\text { arenas }\end{array}$ & & & \\
\hline
\end{tabular}

Table 2 Four actions framework of Southwest airlines blue ocean strategy (Kim and Mauborgnered 2005)

\begin{tabular}{llll}
\hline Eliminate & Reduce & Raise & Create \\
\hline Meals & $\begin{array}{c}\text { Price versus } \\
\text { average } \\
\text { airlines }\end{array}$ & Friendly service & $\begin{array}{c}\text { Frequent } \\
\text { point- } \\
\text { to-point } \\
\text { departures }\end{array}$ \\
$\begin{array}{l}\text { Lounges } \\
\begin{array}{l}\text { Seating class } \\
\text { choices }\end{array}\end{array}$ & Speed & Ticketless \\
\begin{tabular}{l} 
Hub connectivity \\
\hline
\end{tabular} & & & Culture \& Fun \\
\hline
\end{tabular}

Here is one example of a blue ocean company, Cirque du Soleil, Table 1 (Kim and Mauborgnered 2005). It is a Canadian entertainment company and the largest contemporary circus producer in the world. The industry was suffering from steadily decreasing audiences and, in turn, declining revenue and profits. The company created a whole new customer of adults in an industry where the traditional customers were children.

Another typical example of blue ocean company is Southwest airlines, (Table 2), in an industry where there is fierce competition. Southwest Airlines created a Blue Ocean by breaking the trade-offs customers had to make between the speed of airplanes and the economy and flexibility of car transport (Kim and Mauborgnered 2005). To achieve this, Southwest offered high-speed transport with frequent and flexible departures at prices attractive to the mass of buyers. The value curve of Southwest Airlines differs distinctively from those of its competitors. Its strategic profile is a typical example of a compelling Blue Ocean Strategy (Kim and Mauborgnered 2005).

For ordinary airlines passenger travel value could be expressed in terms of going from 'A' to ' $\mathrm{B}$ ' destination on time and safely. Lounges and seat choices might be luxuries which they may not will to pay extra.

Here is more example of Blue Ocean Company that has managed to create new market space in service industry. Airbnb is a typical example of a blue ocean company which is information technology based. Airbnb has managed to create a new market in Hospitality industry where there is fierce competition among the players, such as Hotels, Hostels, and bed and breakfast. Airbnb has fully information-based offerings using digital channel.

The table below (Table 3) shows blue ocean strategy canvas for Airbnb.

The blue ocean strategy focuses on rebuilding the boundaries of the market, the strategy also basis on creating new growth and new value by mitigating the weakness of the product and services so that to create a new demand through value innovation (Abdulraheem 2016). Once a firm is in Blue Ocean it is no more in the crowd, where there exists fierce competition for already available market demand. Guillaume Nicolas (2011) listed some of the main reasons to develop a Blue Ocean Strategy.

These are reasons to develop blue ocean strategies: Supply exceeds demand in lot of industries, globalization in which globally networked market space, with customers highly informed about products and services value proposition and pricing, would lead to fierce competition among suppliers, price wars, low profit margins, niche markets disappearance, norms and regulations, brands are more and more similar so the selection is based on the price, commoditization of products and services.

As it is mentioned on the introduction part of this study lean as a strategy option is a contemporary endeavor in lean community. Lean thinking is about waste reduction and a paradigm shift in problem solving and creation of value for customers, using lean principles, which are: definition of value, identification of value stream, organize around flow, responding to pull, pursuit perfection Womack and Jones (1996) by doing so the firm could consider focusing on value adding components of the service and product delivery and eliminating and minimizing those
Table 3 Four Actions framework of Airbnb blue ocean strategy, (Leavy (2018)

\begin{tabular}{llll}
\hline Eliminate & Reduce & Raise & Create \\
\hline Big name hotels & Price & Visual designs & Homestay accommodation \\
& $\begin{array}{c}\text { Quantity of } \\
\text { services } \\
\text { Safety }\end{array}$ & Review of other guests & Interaction between hosts and guests \\
& $\begin{array}{l}\text { Variety of room types } \\
\text { Social network influence }\end{array}$ & $\begin{array}{l}\text { Connect with local culture } \\
\text { Sense of belonging }\end{array}$ \\
\hline
\end{tabular}


activities which have no value for customer or taken as granted.

Lean strategy basis its competitive advantage on the workforce engagement and involvement. One of the two pillars of lean philosophy is respect for people, Liker (2004). It sounds logical that any strategic direction set by businesses need every employee's involvement and commitment to implement and would take advantage of the strategic competitive edge envisioned. Lean is a continuous improvement journey targeting perfection. In real sense perfection is unattainable, but the idea behind perfection is not to be complacent with the improvement achieved and continuously striving for value innovation from the perspective of the firm's customers.

Kim and Mauborgne (2005) compared the two strategies, Blue and Red Ocean. As this report includes lean as one strategy option the strategies comparison could be improved and compared as shown in Table 4.

The creators of Blue Oceans didn't use the competition as their benchmark. Instead, they followed a different strategic logic that Kim and Mauborgne (2005) call it value innovation. Value innovation is the cornerstone of blue ocean strategy. Focus in value innovation is creating a leap in value for customers and the company, thereby opening up new and uncontested market space. Value innovation occurs when companies align innovation with utility, price, and cost positions. If companies fail to anchor innovation with value in this way, technology innovators and market pioneers often lay the eggs that other companies hatch (Kim and Mauborgne 2005).

One of the founding principles where Blue ocean strategy is based on is Value innovation. In today's highly competitive environment the goal of each organization is to defeat competition and win new customers (Urbancova Hana 2013). A learning organization, with knowledgeable workforce, represents a tool for innovative firm. Urbancova Hana (2013) argues that knowledge is an important element in the process of innovations. As shown in Fig. 1, innovation is about doing things in a new and better way than the existing norm, it is about taking advantage of new development

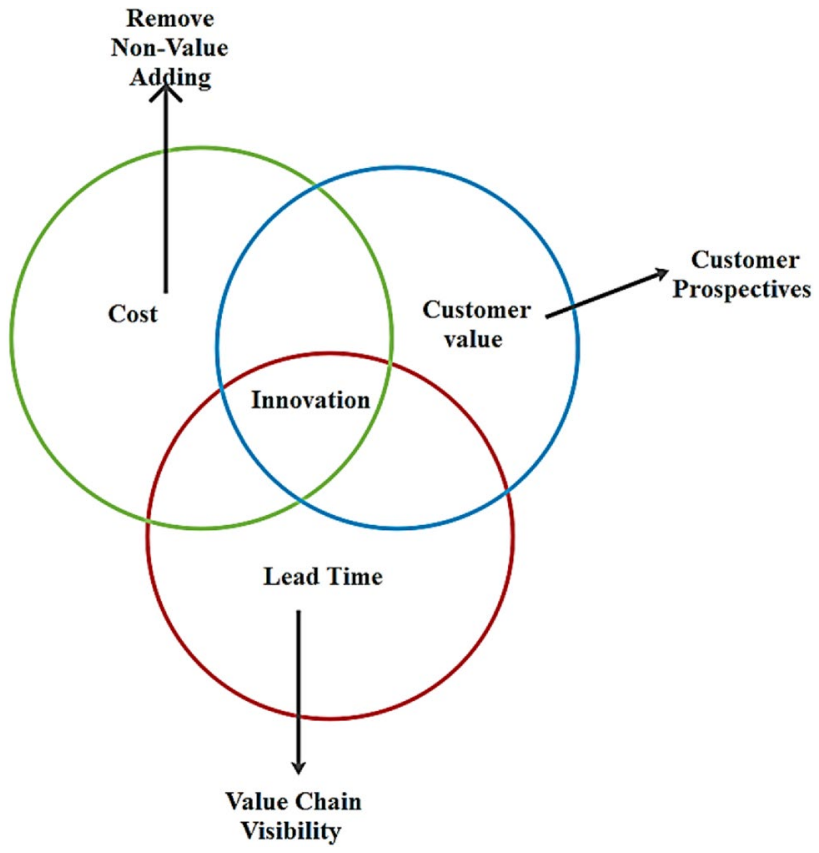

Fig. 1 Customer Value-innovation adapted from (Kim and Mauborgne 2005)

in technology to create and innovate new products, service delivery, service, new method of management, new business system in general, etc. (Kim and Mauborgne 2005).

Irrespective of the size of the firm, innovation would give a cutting-edge advantage over the competitors. Eboreime and Gbandi (2014), asserted that applying the Blue Ocean Strategies for small and medium enterprises, SMEs, in the form of niching and customization would help SMEs to compete with larger companies and meet up with global competitiveness.

Applying strategy Value innovation on small and medium enterprises could be cost minimization and at the same time could lead to differentiate these enterprises (Hannelize and Chipego 2012). Mukesh et al. (2013) analyzed firm's leadership, human capital management, organizational culture, design and systems, and concluded that all collectively

Table 4 Comparisons of Strategy options adapted from (Kim and Mauborgne 2005)

\begin{tabular}{|c|c|c|c|}
\hline Red ocean & Blue ocean & Lean strategy & Core Competency \\
\hline Compete in existing market space & $\begin{array}{l}\text { Create uncontested/new market } \\
\text { space }\end{array}$ & Continuous innovation & Access to a wide variety of market \\
\hline Beat the competition & Make the competition irrelevant & Stakeholder collaboration & Difficult to imitate by competitors \\
\hline Create a value -cost trade off & Break the value-cost trade off & Eliminate nonvalue add activities & $\begin{array}{l}\text { Perceived customer benefits of the } \\
\text { end products }\end{array}$ \\
\hline Competitive advantage & Value innovation & Customer value & Multiple resources and skills \\
\hline Segmenting existing customers & Attract non-customers & Process streamline & Build core competencies \\
\hline Exploit existing demand & Create and capture new demand & People centric & $\begin{array}{l}\text { Core competence to raise values of } \\
\text { customers }\end{array}$ \\
\hline
\end{tabular}


merge to create a more dynamic and responsive organization which is far more proficient at building unique resources and capabilities, which can then be leveraged to create new market opportunities with high competitive entry barriers.

A learning organization with unique core capability, compared to the competition, would position it in a competitive edge to outperform the competition. In this regard one of the crucial tools at firms' disposal is the application of ICT in business processes and service delivery. Mahmood et al. (2010) argue that development in information communication technology, the business environment that we knew a decade ago is totally different from the current business environment, comprehensive change in business background and emerge of computers, internet and big data, the business structure and needed information have changed, the competitiveness as a major factor for business existence mainly depends on information technology challenges.

The differentiating characteristics of the three strategy options are illustrated as below. Time and again the purpose of this study is not to choose one strategy option from the other strategy choices discussed here but to review each one of them and the decision which one to use is based on situational approach of a particular organization and in some cases it could be commanding to use multi-strategy options. The authors of this paper argue that flexibility and agility in business strategy formulation and implementation would give a competitive advantage for a firm to align firm's internal capability and strength to the external market dynamics.

The authors of this paper are optimistic about the business market environment in Sub-Sharan Africa, with all challenges and ease of doing business due to Unemployment and underemployment, underinvestment in infrastructure, fiscal crises, political change, climate change, corruption, tribal conflict, political instability, etc. Thus, the discussion of this paper could work as a potential perspective for African business leaders to consider Situational and Mixed business strategies that could capture the context of SubSharan African business environment.

The authors of this paper highly recommend companies to avoid heads on competition where each competitor bases their competition on the same factors. For example, if once they start to compete on price, this might lead to loss for every player in the industry, which would lead to a 'zero sum game'. Thus, every firm need to uniquely position its company so that it serves its respective customers with added value.

Nitin Zaware (2016) lists the key differentiating characteristics of Blue Ocean Strategies. These are: Non existing industries, undefined market space, undefined industry boundaries, Unknown competitive rules, High profit \& growth opportunity, Value innovation, Innovation \& creativity, create a market, develop future demand, creating future customers.

Likewise, Nitin Zaware (2016) lists the key differentiating characteristics of Red Ocean Strategies. These are: Focus on existing customers, existing industries, defined market space customers, defined industry boundaries, known competitive rules, Low profit growth opportunity, competitive advantage, Low cost or differentiation, Beat the competition, exploit existing demand.

Moreover, the red ocean strategy has its own characteristics such as compete in existing market, fierce competition, exploit existing demand (fight for own share of the pie), value -cost trade off, etc. The lean strategy process is shown in Fig. 2.

Toyota motor company is the model lean manufacturing company commonly mentioned as lean success story. Toyota calls the practice, Toyota Production system (TPS). After World War II, Toyota went nearly bankrupt. Toyota has used the TPS philosophies to focus on customer value, quality, waste minimization, process optimization and streamline processes by reducing non-value add activities.

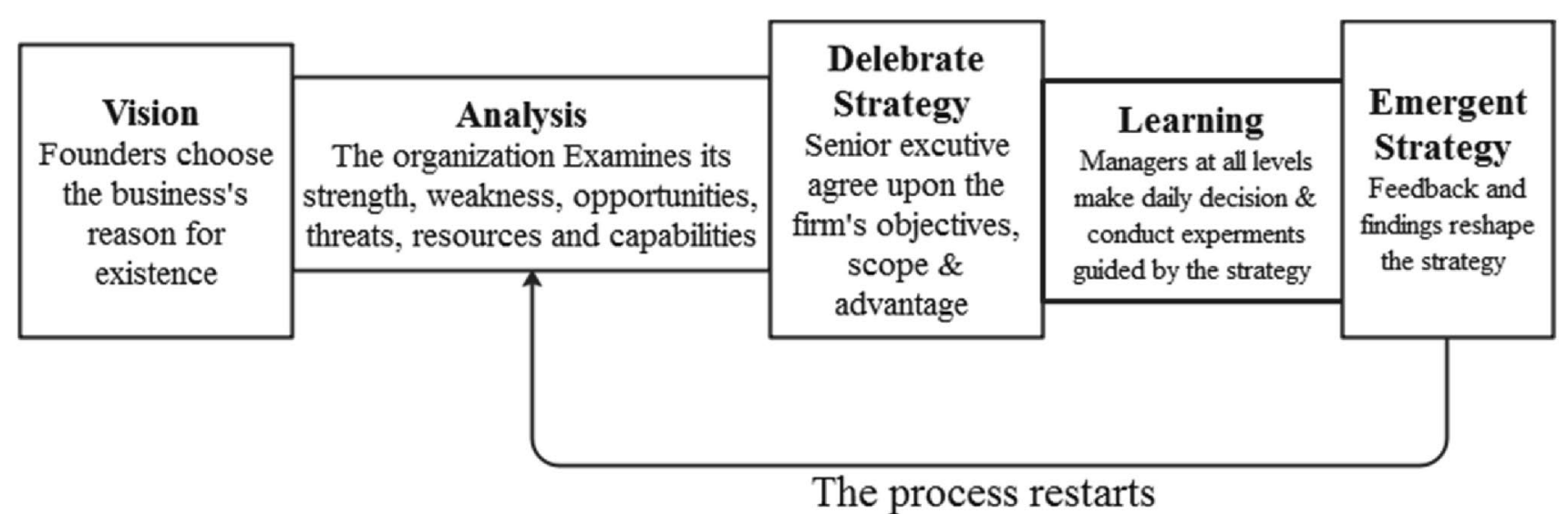

Fig. 2 The lean strategy process (David Collis 2016) 
That is how the company has become the market leader in an industry where there is fierce competition (Michael et al. 2017; Michael 1990).

Lean uses a people-centric approach to strategy that respects people by continuously challenging them to become the best that they can be and finding ways to create more value for customers.

Nitin Zaware (2016) further lists (Table 5) to elaborate the difference between Red, Blue Ocean. The authors of this paper added the lean strategy as an option in organizations strategy options. Factors used for assessment purposes are; industries, competition, demand, alignment of system, profit opportunities, customer focus, and system approach, etc. Table 5 describes assessment among Red Blue Ocean and lean Strategies.

\section{Research Methodology and Material}

Whether it is for profit or non-profit every organization has mission, vision, and core values that are achieved through time using organization strategy and every resource at the exposure of the organization that would be mobilized to execute and achieve the envisioned strategy. High impact factor academic research journals were reviewed to compare the various strategy options available for organization to implement. Some of the academic research database searched was: Science direct, Springer, Emerald etc. The key words and phrases used in search were strategy formulation, strategy implementation, strategy and firms market environment, red ocean strategy, blue ocean strategy, lean strategy, industry market space, industry demand, competitive advantage, market competition, value innovation, value proposition, service delivery and combination of the above words.

Special focus was given for academic articles published in years after 2000. In selecting an article for further review, relevance of the article to the research topic was evaluated first based on the title then the abstract and introduction, with these criteria matching articles were further reviewed to see its significance for inclusion as a reference material. Articles that fulfilled these requirements were thoroughly reviewed including the main body part. The most important gap found on literatures were focusing on one kind of strategy option and promoting as if one strategy option would fit for every situation and not keeping strategy documents flexible and agile for continuous improvement to adapt to dynamic external market environment. Moreover, there is a tendency of benchmarking the market leader to copy its way of doing business which has a risk of competing with same factors that exacerbate heads on competition. Thus, every company has its own way of strategically and uniquely positioning its business direction to serve its perspective

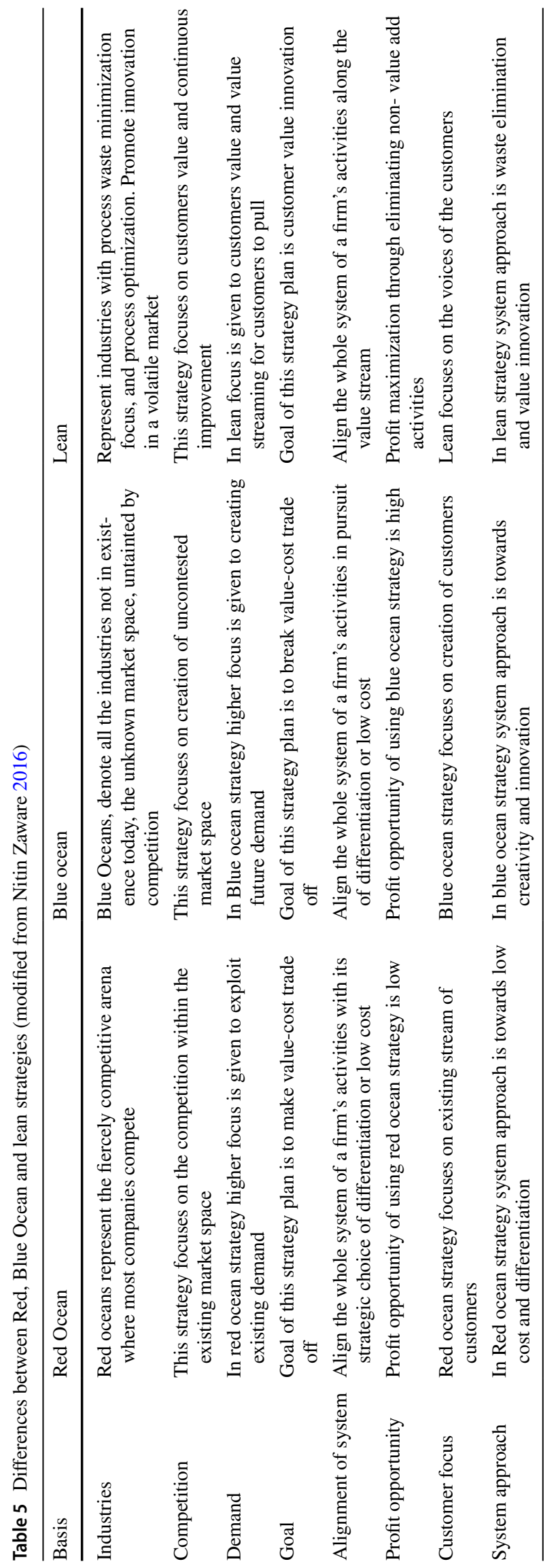


customers. Figure 3 shows the stepwise processes followed for article review.

\section{Result and Discussion}

The common norm when it comes to devising business strategy is to consider value-cost trade off. But, the contemporary approach to business strategy is to pursue differentiation and low cost simultaneously, using value innovation. Regardless of the establishment of an industry, whether it has saturated market space or not, we have plenty of practical examples from various industries that are growing new demand and creating a new market space is a possibility. Red Ocean Strategy exists within the boundary and plays by the existing rule and competes for the demand available in the market, while Blue Ocean Strategy strives in creating new demand and exists beyond the boundary on the Blue Ocean where it is not inhabited by 'bloody sharks' who just know the rule of survival of the fittest.

Likewise, lean basis its strategy on customer value and has people centric strategy mainly focusing on process waste elimination and optimization through continuous improvement and customer value innovation and continuously learning from challenges and problems, by using various problem solving method, such as PDCA, A3, KATA, Pareto analysis, 5 WHYs, spaghetti diagram etc.

Raman (2014) argues that every strategy carries its own significance and suitability depending on the market size, nature of product and services in supply, and generally on the market environment and nature of the industry.

Ning He (2012) asserts that competitive advantages of an organization have a life cycle which starts from a planned selection and subsequent resource accumulation; however, enduring success requires sustainable competitive advantages and implies continuous improvement and innovation. Sadia Majeed (2011) states that almost in all organizations there is a good association between company's competitive advantage and its performance. Both authors, Ning He (2012) and Sadia Majeed (2011) emphasis on the importance of competitive advantage, on firm's sustainable business growth and profitability, without framing a systematic approach for attaining the same. The authors have not framed a practical approach how this competitive advantage might be achieved.

Kim and Mauborgne (2005) argue that without analytical frameworks to create Blue Ocean and principles to effectively manage risk, creating Blue Ocean has remained wishful thinking that is seen as too risky for executives to pursue as strategy. As demand for a product and services erodes, competition becomes harder and harder, in each passing day. A way to avoid this heavy competition is to look for uncontested market space (Kim and Mauborgne 2005). In contrast, competitive strategy emphasizes the inevitability of longterm competition among relatively homogeneous contenders pretending that market conditions are stable (Porter 1980; Andrew et al. 2016). How fast a new market space disappears determines the relevance of the Blue Ocean Strategy. In other words, it is determined by how long new market space remains sustainable because uncontested or unsuccessfully contested. In yet other words, it is determined by how long it takes for a Blue Ocean to turn Red.

Firm's need to evaluate the competitiveness of the business environment they are operating into understand the nature of the competitive forces (Fig. 4) operating in the market space so that they can continuously revise the business strategy to capitalize on the firm's strength and improve the weak positions.

In contemporary business strategy the concept of competitive advantage has gotten major attention, but the real question for everyone in strategy agenda is how to attain a competitive advantage. Joy et al. (2013) argue that a product with ability to standout in a competitive category would give a competitive advantage for a firm. Differentiation is when a firm or brand outperforms rival brands in the provision of a feature(s) such that it faces reduced sensitivity for other features (Sharp and Dawes 2001; Joy et al. 2013).

Every Blue Ocean Company would ultimately reach to the level of Red Ocean category as every organization carries the motive to earn higher profits (Kim and Mauborgne 2005). Companies in Red Ocean operate under conventional game rule, which is set by the competition. The target here is beating the competition and fighting to get once market share by snatching demand from the competitors. In contrast, Blue Ocean does not use the competition as a benchmark but make the competition irrelevant by creating a new market space.

Lean is relatively new venture in strategy option mainly focusing on waste elimination, process optimization, customer value innovation using core philosophies of continuous improvement and respect for people.

The following qualitative strategy option selecting factors could be used to evaluate the external market environment and decide to simulate the scenario and select the potential winning competitive strategy (Table 6). The list is by no means exhaustive.

The authors of this study developed a strategy framework model to illustrate the process of strategy formulation from the perspective of customers' value, product and service delivery innovation and companies' competitive advantages, and companies' strategic unique position in the business market environment under the industry where it operates. Some of the words and terms used in the model development are discussed below.

The model, Fig. 5, starts with the organization's vision and Mission considering the organizations current state, core 


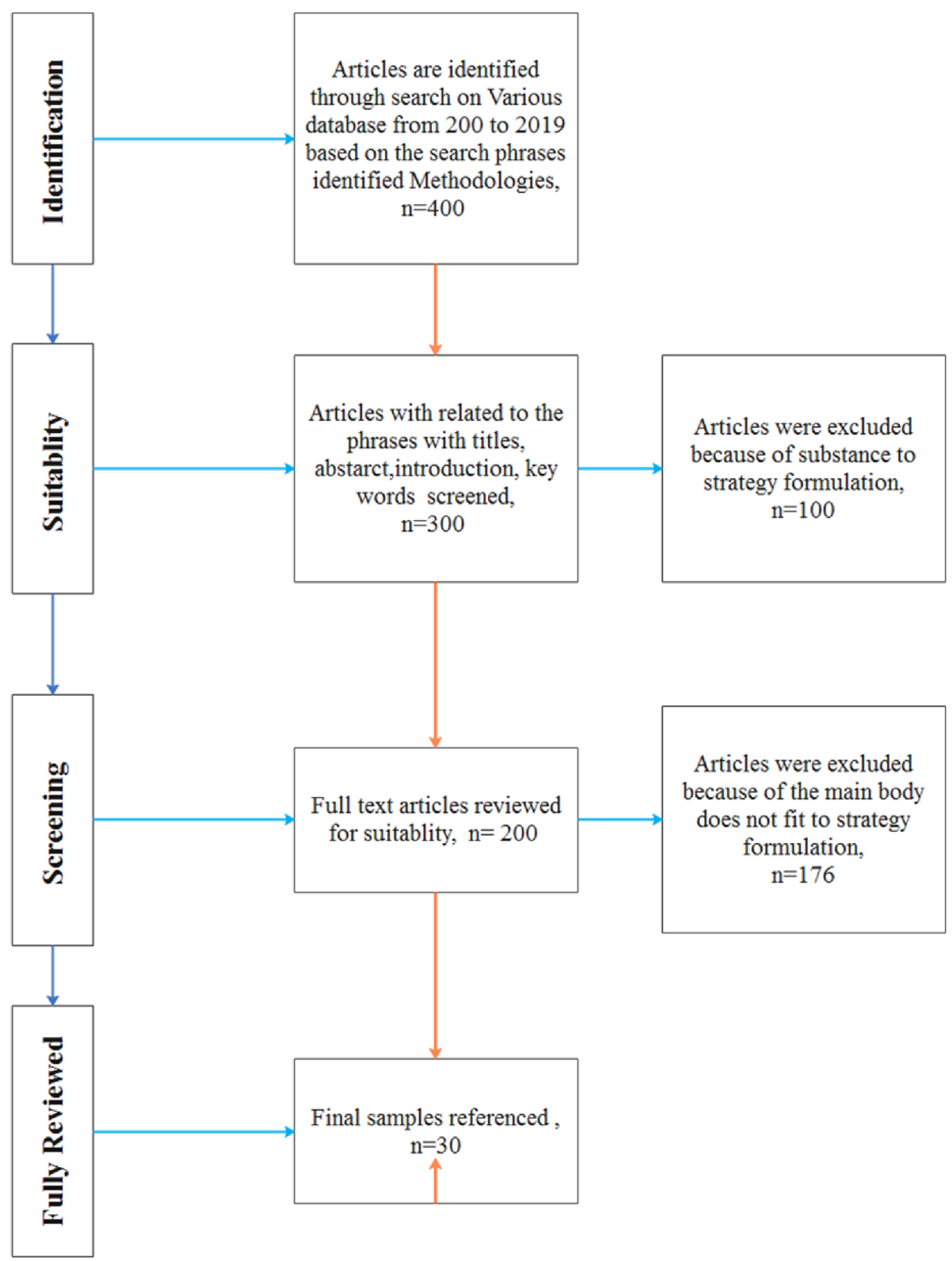

Fig. 3 Literature collection and screening research framework

capabilities and the general stakeholders' expectations, and the values from the customer perspectives. The winning secret in an organization short term and long-term endeavor is its ability in solving customers' problem and its culture of problem solving and continuously learning from the process.

Taiwo et al. (2016) assert that vision and mission statements that were well defined and implemented could bring a shared vision across the organization employees in their day-to-day activities and promote in the fulfilment of organizational goals with the mission and vision as a guiding light.
Kaizen a Japanese word meaning $\mathrm{KAI}=$ Change and $\mathrm{ZEN}=$ for better. The Kaizen management originated in the best Japanese management practices and is committed to the improvement of productivity, efficiency, quality and, in general, of business excellence. The KAIZEN methods are recognized as methods of continuous improvement, through small steps, of the economical results of companies (Titu et al. 2010).

The historical traces of the stakeholder management date back to the 1960s when academics at the Stanford Research 


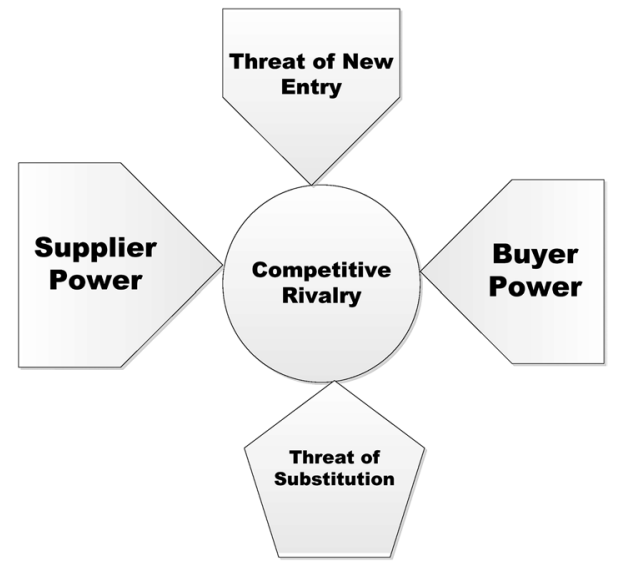

Fig. 4 Porter's five forces (Porter 1979)

Institute (SRI International, Inc.) first expressed what was considered at the time to be a controversial proposal (Stoney and Winstanley 2001 cited in Preble 2005).

Preble (2005) has listed some of the stakeholders that have expectation on the activities of an organization, these could be: local community, owners, consumers, customers, competitors, media, employees, special interest groups, environmentalist, suppliers, governments, etc. Without stakeholders' support and consent, organization would not meet their expectations.

Deming's (1986) PDCA cycle made to represent the center as a sign the strategy formulation process need to be continuously improved. The current state of the industry is a very good context that shows the current state of the market demand and customers segmentations.

The continuous improvement in Strategy formulation, through Kaizen (Smadi 2009; Imai 1986; George 2007) could give an organization the flexibility, agility and emergent nature of the strategy formulation to capture the dynamic nature of the market demand and customer segmentations.

Consequently, the model proposed is a generic strategy formulation framework that could be used by businesses to have a general picture of a business market environment where businesses can formulate a situational business strategy that could place a company in a unique strategic position to serve its perspective customers and achieve its business goals.

The organization's internal and external environment is important to strategy formulation. The strategic analyses capture the strength, weakness, opportunity and treat (SWOT). It is imperative to gear the strategic direction of strategy formulation on organizations soft skill, workforce capabilities and other resources.

PEST analysis (Fig. 6) is used to recognize the effect of Political, Economic, Social and Technological changes in a business external environment in implementing business strategy. Using PEST analysis firms could identify potential threats and opportunities to firms' strategy so that to capture the opportunities and avoid the threat.

Ideal strategy without proper implementation process and continuous follow up measures could not bring the result anticipated. The normal trend is Strategy formulation is that it emanates from top management as the top management are the one setting the business direction of the organization where the firm competes, what product and service offering to choose, the future direction of the company, the competitive unique positioning of the firm that is geared to internal capability and external business market environment.

Even if, Strategy sources from top, clear communication and buy-in by all involved employees and players is crucial for achieving the business goals to be achieved through the company's strategy.as shown in Fig. 7, it illustrates Strategy Options implementation processes.

\section{Conclusion}

Business strategy is one of the most important management tools, that sets the business direction on the right track, and a tool which enables to cruise the 'business ship' against the tide and in 'the Pacific' ocean with less risk of sharks and fierce competition for existence. Nevertheless, the current reality of business environment dictates that business competition in one form, or another would exist. Thus, businesses need to analyze the internal
Table 6 Illustrative example of possible matching scenarios for strategy options selection

\begin{tabular}{lllll}
\hline Business market Situations & \multicolumn{2}{l}{ Strategy options } & & \\
\cline { 2 - 5 } & Red-ocean & Blue ocean & Lean strategy & Mixed \\
\hline Strategy in era of economic upturn & VH & M & H & H \\
Strategy in era of economic downturn & M & H & VH & H \\
Strategy for developing nations, e.g. Sub- & M & H & H & VH \\
$\quad$ Sharan Africa & & & M & H \\
VUCA world e.g., COVID-19 & H & VH & M
\end{tabular}

Scale for matching: VH, very high; H, High; M, Medium 


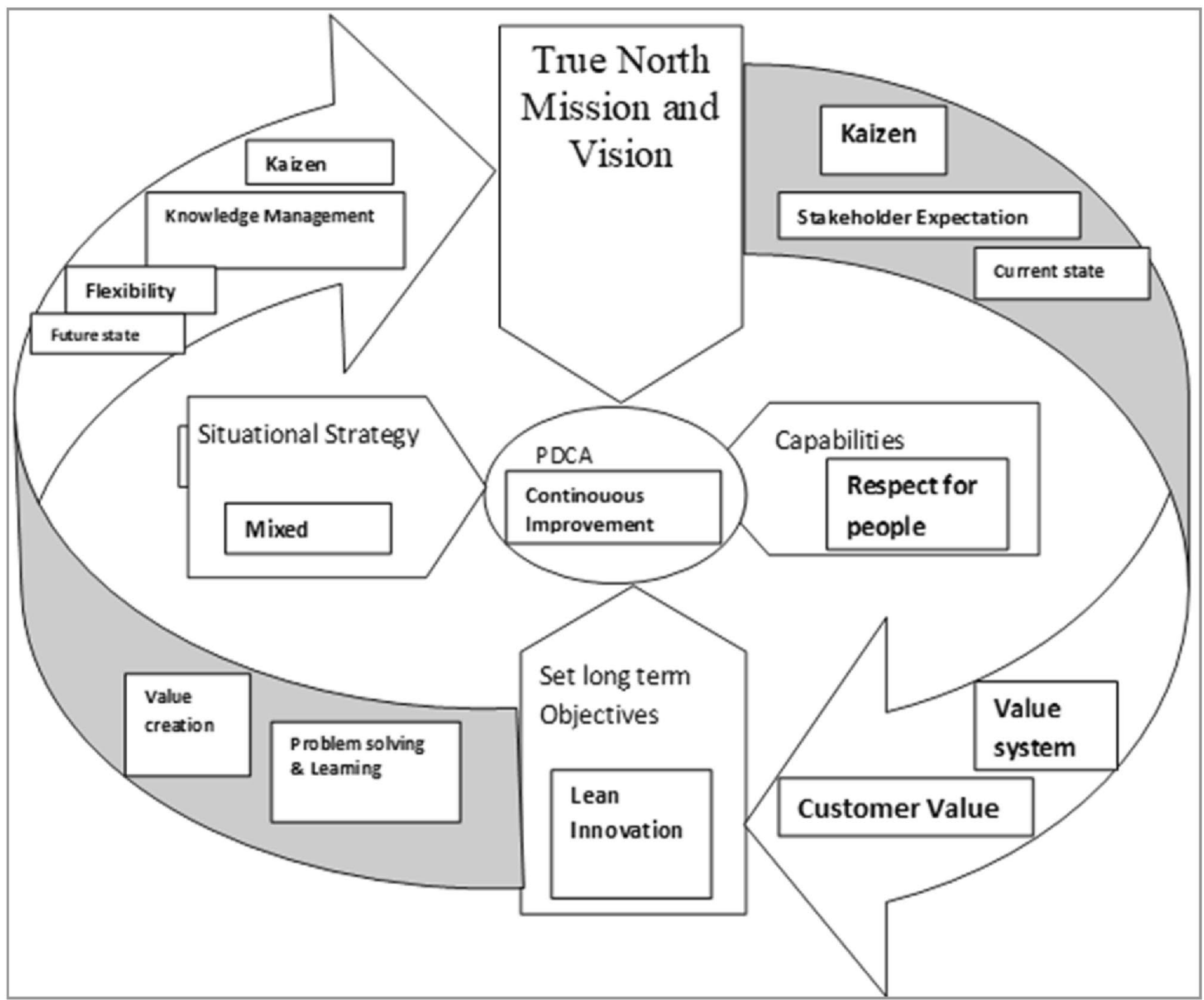

Fig. 5 A conceptual framework of strategy formulation

SWOT Vs PEST Analysis

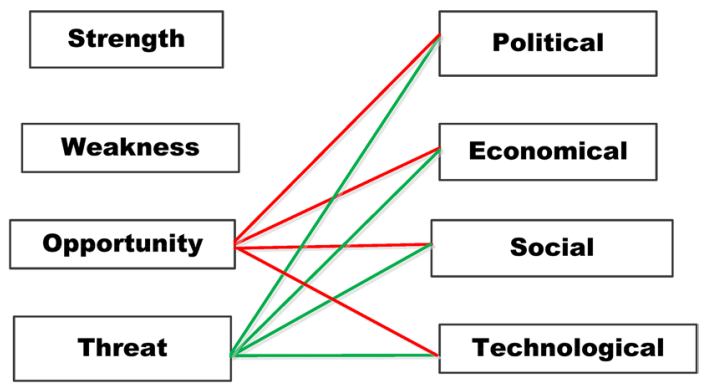

Fig. 6 SWOT analysis VS PEST analysis (Web 1 2020) and external market where they operate and formulate their business strategy as the situation dictates.

Business strategy gives companies the 'radar' to navigate the market environment 'sea' peacefully damping the effect of the 'sea wave' so that the company would be strategically and uniquely placed to serve its customers and accomplish its own goal of establishment.

Every business strategy considered in this reviewBlue ocean, Red ocean, Lean strategy-have their own pros and cons. For example, the red ocean strategy market is well established, and the market suppliers know what products and services the customers want. The unfortunate thing about this well-established market 
Fig. 7 Strategy options implementation processes

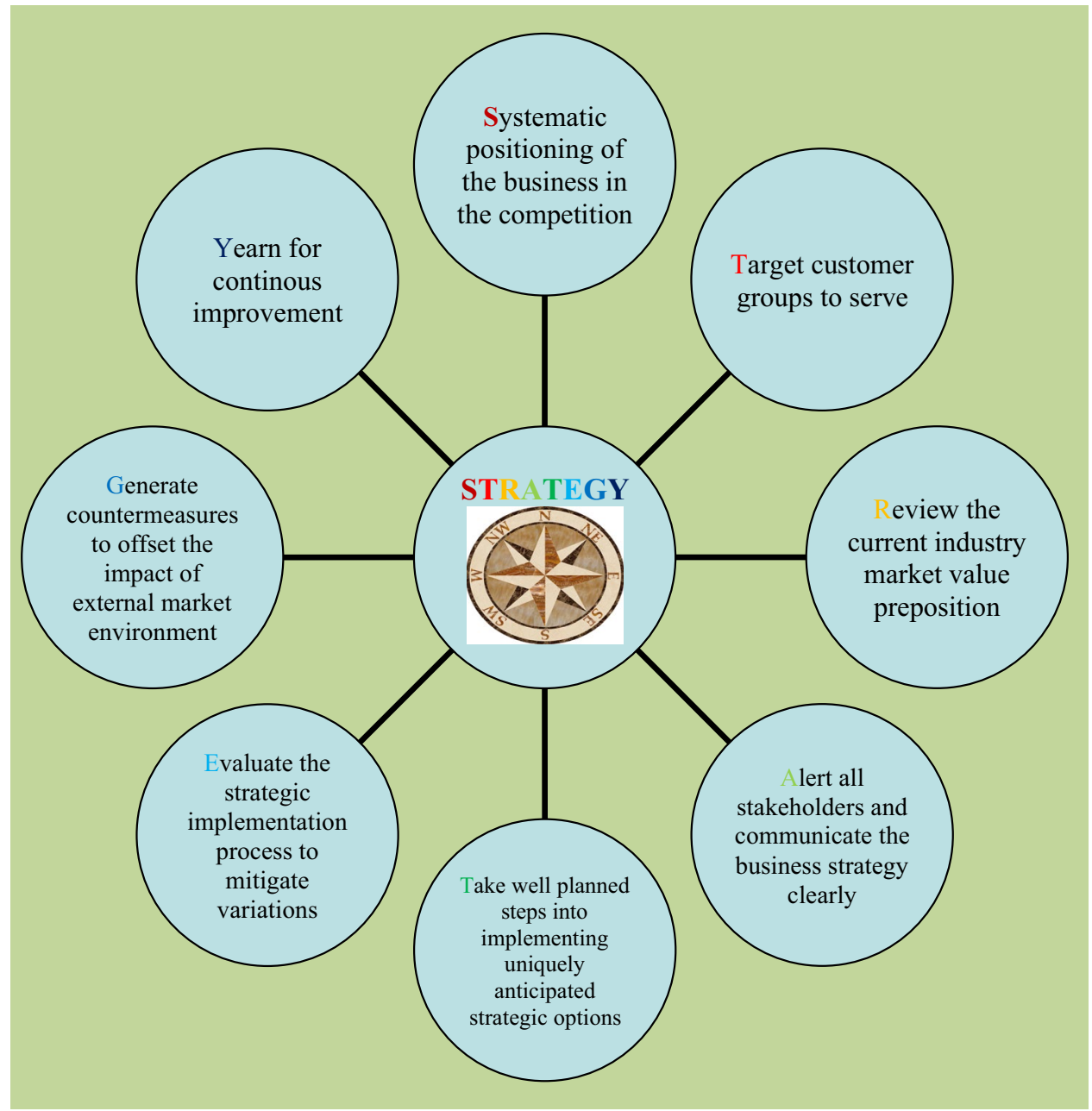

could be the existence of market leaders who will be very difficult to beat. Likewise, the blue ocean strategy could enable generating high profit margin in a new market by innovating new brand product and services. The shortcoming with this kind of business strategy could be the unforeseen risks of new market, and the eventual change of blue ocean strategy to red ocean strategy.

Similarly, lean strategy is arguably a strategy option where organizations benefit from waste elimination, process optimization, and customer value innovation through continuous improvement and employee engagement. Shortcomings of lean strategy: value chain dependent, needs a complete cultural change and employee mindset change to see its result. Unforeseen supply chain disruption could result in products and services provision. In lean practice it is customary to keep the inventory level as low as practically possible, using the practice of Just-in-time (JIT) philosophy. For instance, the global COVID-19 pandemic has resulted in supply chain disruption as countries are closing sea and air borders to contain the outbreak.
COVID-19 is a treat to the global health and economy in general and Sub-Sharan Africa in particular. The region has the least developed health infrastructure. Given the magnitude of the pandemic, it could pose a real challenge to social well-being and economic impact. The lockdown measures that have been taken by the region's governments have already impacted the regions population that millions live under abject poverty in day to day subsistence income. The longer the lockdown the higher would be the impact on the general social and economy of the region, in which case millions more may fall into poverty. Time will tell!

The study, in general, recommends further researches to be conducted on the situational and mixed strategies for in depth investigation with primary and empirical data to validate the approach's application in a dynamic business environment. Potential cases could be done in Sub-Sharan Africa. In addition to this future research area the authors would like to recommend future research area related to this study in the area of sustainable strategies to capture the scope in social, economic and environment dimensions integrating with market situational analysis. 


\section{Key Questions Reflecting Applicability in Real Life}

The real-life applicability of this study could be addressed by raising key questions of the dynamic nature of a business environment business have to face as follows:

1. How can Sub-Sharan African countries businesses strategically and uniquely position themselves in a global market environment?

2. How can firms in Sub-Sharan African countries analyze strategy to evolve options to cope with disruptive forces?

3. How can firms in Sub-Sharan African countries improve strategy process of competitiveness Assets-ProcessesPerformance (APP) framework (Momaya 2001) to improve market and financial performance of the firm?

4. What strategic choices can enhance sustainability performance of the firm?

5. Is generic strategy options fit enough for the enormous challenges businesses in Sub-Sharan African countries undergoing through?

6. How does Situational and Mixed Business Strategy could be the perspective for the current dynamic market environment with full of disruptions never before?

Acknowledgements We wish to thank Addis Ababa University School of Mechanical and Industrial Engineering, especially to Industrial Engineering Department staffs and administration for providing us with attractive office environment and office facilities while we were conducting this research. We also would like to extend our sincere gratitude to JGBC editor and the reviewers for their valuable input and comme nts to make this paper to be here in this high impact journal. The paper would have not been here in this journal that frequent comments were not obtained for the editor and reviewers to enrich the contents of the paper.

\section{References}

Abdulraheem, A. A. (2016). Market knowledge, blue ocean strategy, and competitive advantage (direct and indirect relationships and impact). Universal Journal of Management, 4(4), 141-160.

Acha, L., et al. (2018). Africa's business revolution: how to succeed in the world's next big growth market. New York: Harvard Business Review Press.

Al Smadi, S. (2009). Kaizen strategy and the drive for competitiveness: Challenges and opportunities. Competitiveness Review, 19(3), 203-211.

Alukal, G. (2017). Lean Kaizen in the 21st century. Quality Progress; Milwaukee, 40(8), 69-70.

Andrew, B., André van, S., Roy, T. (2009). Blue Ocean versus competitive strategy: Theory and evidence, erasmus research institute of management (ERIM).

Andrew, B., Van Stel, A., \& Thurik, R. (2016). Testing the validity of blue ocean strategy versus competitive strategy: An analysis of the retail industry. International Review of Entrepreneurship., 14(2), 123-146.
Arnoldo, H., \& DEAN, W., II. (2001). Dean and company, Virginia, the delta model-discovering new sources of profitability in a networked economy. European Management Journal, 9(4), 379-391.

Collis, David. (2016). Lean Strategy. USA: Harvard Business School.

Eboreime, Ohimai Friday, \& Gbandi, Eleazar Chibuzor. (2014). Blueocean strategy: The strategic logic of high growth for small and medium enterprises in Nigeria. IOSR Journal of Business and Management (IOSR-JBM) Ver. I, 16(5), 01-04.

Edwards Deming, W. (1986). Out of the crisis. Cambridge.: Massachusetts Institute of Technology, Center for Advanced Engineering Study.

Guillaume, N. (2011). The evolution of strategic thinking and practices: Blue Ocean Strategy Master's program in Leadership and Management in International Context. Växjö: Linnaeus university, school of business economics.

Hambrick, D. C., \& Fredrickson, J. W. (2005). Are you sure you have a strategy? Academy of Management Executive, 19(4), 51-62.

Hannelize, J., \& Chipego, Z. (2012). Reaping the benefits of value innovation: Lessons for small agribusinesses in Africa. African Journal of Business Management, 6(33), 9510-9523.

Hanningtone, J. G., Miemie, S., \& Elroy, E. S. (2013). Creating a sustainable competitive advantage at a high performing firm in Kenya. African Journal of Business Management, 7(21), 20492058. https://doi.org/10.5897/ajbm2013.6974.

Hasan, R. U., \& Chyi, T. M. (2017). Practical application of Balanced Scorecard - A literature review. Journal of Strategy and Performance Management, 5(3), 87-103.

Hansen, E. G., \& Schaltegger, S. (2016). The sustainability balanced scorecard: a systematic review of architectures. Journal of Business Ethics, 133, 193-221. https://doi.org/10.1007/s1055 1-014-2340-3.

Ryanair (2019). Ryanair SWOT analysis - Michael O'Leary's maniacal focus on being the lowest cost producer, accessed online from https://centreforaviation.com/analysis/reports/ryanair-swot-analy sis--michael-olearys-maniacal-focus-on-being-the-lowest-costproducer-96465.

Imai, Masaaki. (1986). Kaizen: The key to Japan's competitive success. New York NY: McGraw-Hill Publishing Company.

James, W. P., Jones, D. T., \& Roos, D. (1990). The machine that changed the world: the story of lean production, Harper Perennial modern classics. Cambridge: The MIT international motor vehicle program.

James, P. W., Jones, D. (1996). Lean thinking: banish waste and create wealth in your corporation. https://doi.org/10.1038/ sj.jors. 2600967.

Joy, I. D., Oluwole, I., Ibidunni, O. S. (2013). Product differentiation: a tool of competitive advantage and optimal organizational performance(A study of Unilever Nigeria PLC), European Scientific Journal, vol 9, No.34 ISSN: 1857-7881 (Print) e-ISSN 1857- 7431

Kim W. C., Mauborgne, R. (2005). Blue ocean strategy: How to create uncontested market space and make the competition irrelevant, Strategy/Harvard Business School Press, ISBN $1591396190,9781591396192$.

Landry S. (2018). Africa's consumer market's potential: Trends, drivers, opportunities, and strategies. Brookings Institutions' Africa Growth Initiative Report.

Leavy, B. (2018). Value innovation and how to successfully incubate "blue ocean" initiatives. Strategy \& Leadership, 46(3), 10-20. https://doi.org/10.1108/SL-02-2018-0020.

Liker, J. K. (2004). The toyota way, 14 management principles from the world's greatest manufacturer. New York: McGraw-Hill.

Mahmood, H., Salehi, M., \& Bayat, M. (2010). Competitive advantages and strategic information systems. International Journal of Business and Management., 5(7), 158. 
Majeed, Sadia. (2011). The impact of competitive advantage on organizational performance. European Journal of Business and Management, 3(4), 2011.

Michael, E. P. (1979). How Competitive Forces Shape Strategy. Cambridge: The Harvard Business School Publishing Corporation.

Michael, E. P. (1990). The competitive Advantage of Nations, Harvard Business Review, free press, 1990 by the president and fellows of Harvard college.

Michael, B., Daniel, J., Jacques, C., \& Orest, F. (2017). The lean strategy: Using lean to create competitive advantage, unleash innovation, and deliver sustainable growth. New York: McGraw Hill Professional.

Mohammad Reza Esmaili G, Kambiz H (2015). Blue Ocean Strategy. Definitions and frameworks, advanced social humanities and management, 2(3), 122-125.

Momaya, K. (2001). International competitiveness: Evaluation and enhancement. New Delhi: Hindustan Publishing Corporation.

Mukesh, S., Andy, F., \& Louis, M. (2013). Building a sustainable competitive advantage. Journal of technology management and Innovation Santiago mayo 2013. https://doi.org/10.4067/S0718 $-27242013000200004$.

Ning, H. (2012). How to maintain sustainable competitive advantages-case study on the evolution of organizational strategic management. International Journal of Business Administration, $3(5), 45$.

Nitin Zaware (2016), Blue and Red ocean strategy, SlideShare.

Porter, Michael E. (1980). Competitive strategy: techniques for analyzing industries and competitors. New York: Free Press.

Prahalad, C. K., \& Hamel, G. (1990). The core competence of the corporation. Harvard Business Review, 68(3), 79-91.

Preble, John F. (2005). Toward a comprehensive model of stakeholder management. Business and Society Review, 110(4), 407-431. https://doi.org/10.1111/j.0045-3609.2005.

Pun, Kit Fai. (2004). A conceptual synergy model of strategy formulation for manufacturing. International Journal of Operations \& Production Management., 24, 903-928. https://doi. org/10.1108/01443570410552117.

Quesado, P. R., Aibar, G. B., \& Lima, R. L. (2018). Advantages and contributions in the balanced scorecard implementation. Intangible Capital, Febrer, 14(1), 186-201.

Raman, R. V. (2014). Comparison between ocean strategies. International Journal of Core Engineering \& Management., 1(8), 44-58.

Rumelt, R. P. (1984). Towards a strategic theory of the firm. Competitive Strategic Management, 26, 556-570.

Sharp, B., \& D, John. (2001). What is differentiation and how does it work? Journal of Marketing Management, 17(7-8), 739-759. https://doi.org/10.1362/026725701323366809.

Smit, A. J. (2010), 'The competitive advantage of nations: is Porter's Diamond Framework a new theory that explains the international competitiveness of countries? Southern African Business Review Vol, 14 Number 1.

Taiwo, A. A., Lawal, F. A., Agwu, P. E. (2016). Vision and mission in organization: Myth or heuristic device? The International Journal of Business \& Management 4(3).

Teece, David, Pisano, Gary, \& Shuen, Amy. (1997). paper dynamic capabilities and strategic management. Strategic Management Journal, 18(7), 509-533.

Titu, M., Oprean, C., Daniel, G. (2010). Applying the kaizen method and the $5 \mathrm{~S}$ technique in the activity of post-sale services in the knowledge-based organization, Proceedings of the International Multiconference of engineers and computer scientists, $2010 \mathrm{Vol}$ III, Hong Kong.

Urbancová, H. (2013). Competitive advantage achievement through, innovation and knowledge. Journal of Competitiveness 5(1), 82-96, ISSN 1804-171X (Print), ISSN 1804-1728. https://doi. org/10.7441/joc.2013.01.06.

Valiollahpour, Morteza, Valiollahpour, Sahar, Hasannejad, Farshid, Hosseini, Seyedeh Maryam, \& Akhavan, Saman. (2014). New approach to strategy at the diamond model based on competitiveness. International Journal of Scientific Management and Development, 2(6), 213-220.

Wang, H. (2014). Theories for competitive advantage. Wollongong: University of Wollongong.

Web 1(2020). https://www.creately.com/blog/diagrams/SWOT-analy sis-Vs-PEST. Accessed March 2020

Wernerfelt, Birger. (1984). A resource-based view of the firm. Strategic Management Journal, 5(2), 171-180.

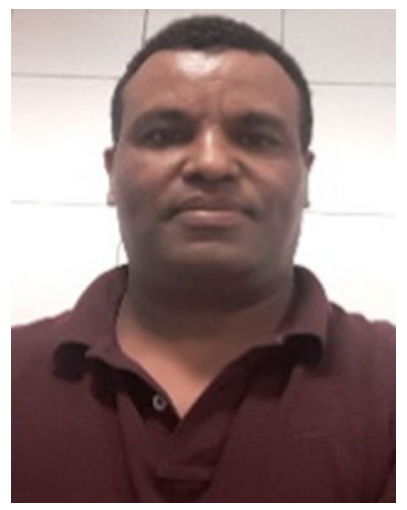

Desalegn Yeshitila Teklegiorgis Is a $\mathrm{PhD}$ candidate at Addis Ababa Univeristy, Addis Ababa Institute of Technology, School of Mechanical and Industrial Engineering. He obtained his Master of Science degree in Industrial Engineering in 2004 from Addis Ababa University. He also obtained MSc in Petroleum Engineering from University of Stavanger, Norway in 2007; in addition to these he obtained MBA from Chifley Business School in Australia in 2013.

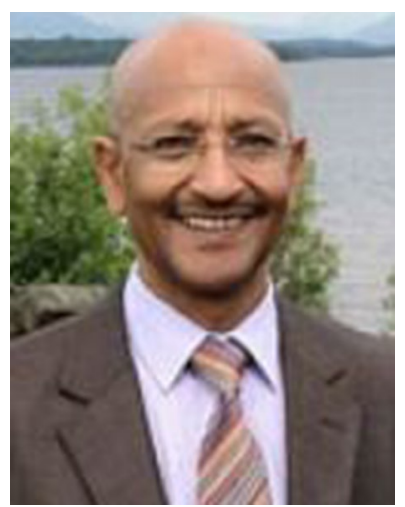

Daniel Kitaw Is Professor of Industrial Engineering (IE) at Addis Ababa Institute of Technology (AAiT), Addis Ababa University (AAU), and an affiliate professor at New Mexico State University, USA. He obtained his BSc in Mechanical Engineering with distinction from Addis Ababa University in 1980, MSc and PhD in IE from Polytechnic of Turin-Italy in 1984 and 1999, respectively. He also received advanced certificate in informatics from Trinity College Dublin (1986). He has advised over one hundred MSc Theses and fifteen $\mathrm{PhD}$ dissertations so far, and currently he is supervising nine $\mathrm{PhD}$ candidates. 


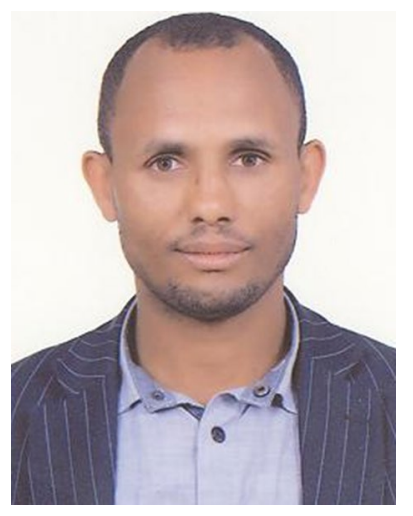

Dr. Kassu Jilcha Sileyew Is a graduate in BSc degree from Bahir Dar University, Faculty of Technology and Engineering in 2006. He obtained his Master of Science degree in 2010 and his Doctor of Philosophy in 2017 in Industrial Engineering from Addis Ababa University (AAU), Addis Ababa Institute of Technology, School of Mechanical and Industrial Engineering. Currently, he is working as an assistant professor of Industrial Engineering at AAU. He has experience of publishing in reputable journals with more than 20 high-impact articles. Also, he is a reviewer at 5 open access journals.

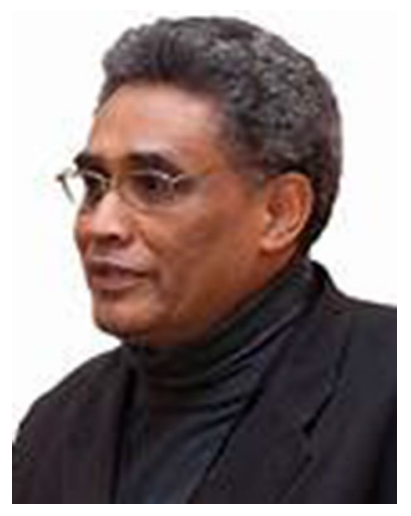

Prof. Muchie Is currently a DST/ NRF Research Professor at the Faculty of Management Sciences, Tshwane University of Technology, South Africa. He previously served as a Director of the Research Centre on Development Studies and International Relations, Department of History, International and Social Studies, Aalborg University in Denmark. Muchie was educated in USA and in Europe. He obtained his MPhil and DPhil degrees in development economics and science, technology and innovation studies from Sussex University, England under the supervision of the renowned innovation scholar, the late Freeman of the IDS/ SPRU. 